\title{
An Empirical Analysis of the Monetary Policy Reaction Function
}

\author{
Felix S. Nyumuah ${ }^{1}$ \\ ${ }^{1}$ Department of Financial Management, Zenith University College, Accra, Ghana \\ Correspondence: Felix S. Nyumuah, P.O. Box SK 237, Sakumono Estates, Tema, Ghana. Tel: 233-243-671-295. \\ E-mail: fsnyumuah@yahoo.co.uk or silverglw7@gmail.com
}

Received: January 19, 2017

Accepted: February 14, 2017

Online Published: January 30, 2018

doi:10.5539/ijef.v10n3p30

URL: https://doi.org/10.5539/ijef.v10n3p30

\begin{abstract}
Monetary policy decisions usually follow a policy rule which shows a consistent response of policy instruments to variations in inflation and economic growth. The aim of this study is to establish the nature of monetary policy in developing countries through the analysis of policy reaction functions. This study uses macroeconomic data from Ghana, a typical developing country. The study employs the Dynamic Ordinary Least Squares Estimation technique and finds the central bank to follow a backward-looking Taylor rule. The evidence is that the central bank follows some form of policy rule and focuses more on past inflation relative to current or expected inflation. The results also indicate that the Bank of Ghana has been pursuing inflation targeting monetary policy. The central bank follows an inflation targeting rule allowing for output stabilisation. The exchange rate also plays a role in this stabilization effort.
\end{abstract}

Keywords: monetary policy rule, inflation targeting, monetary policy, output stabilisation

\section{Introduction}

Friedman (1982) proposed that monetary policy should be based on rules as opposed to the discretion of the authorities. Monetary policy that is rules-based involves the use of formulas or equations to serve as a guide to decision making. Hence, policy decisions can be predicted in a more systematic way. Monetary policy decisions are depicted by a stable relationship which shows a steady reaction of a policy instrument to fluctuations in inflation and economic growth. On the contrary, discretionary monetary policy decisions are more ad hoc and less predictable aimed at fine-tuning the economy in the short-term (Taylor, 2012). Taylor (1993) came out with a policy rule that enables the Federal Reserves adjust its policy rate to respond to lagged inflation and real Gross Domestic Product (GDP) gap. Thereafter, a number of studies have used and developed this policy rule to analyse the actions of central banks in developed countries. Unfortunately, empirical analyses of monetary policy rules of developing countries have been relatively scarce as compared to the advanced countries. This study aims to bridge this gap in the literature by analysing the monetary policy reaction functions of Ghana.

There is a distinction between two types of rules in the literature on monetary policy reaction functions. These are the Taylor rule which is based on the use of the interest rate as a policy instrument to respond to variations in macroeconomic conditions and the McCallum rule which is monetary based. As far as the advanced countries are concerned, Hsing (2004), used a Vector Auto Regression technique to examine the monetary policy reaction function of Japan. The overnight call rate was found to respond positively to shocks to the inflation gap, the output gap, the lagged overnight call rate, the yen depreciation and stock prices. With the exception of the lagged overnight call rate, the exchange rate and the inflation gap proved to be more statistically significant than the output gap and stock prices. Examining a rule-based monetary policy behavior in Russia in order to look at the central bank's response to inflation, the output gap and the exchange rate, Esanoy, Merkl and Vinhas de Souza (2005) find the objective of the Bank of Russia before 1995 to be a reduction in inflation. After 1995, the focus shifted to exchange rate stabilization. Chevapatrakul (2009) adopts a new technique that estimates the reaction of interest rates to inflation and the output gap at various quantile points, in order to test whether there is more aggressive response to inflation as interest rates approach low levels. He finds no evidence in the United States and Japan of greater aggression as interest rates approach the zero lower bound. More recently, Ghatak and Moore (2011) find some interesting differences when examining both the Taylor rule and the McCallum rule as monetary policy rules for the new European Union member states. For the Czech Republic, Poland, Slovakia, and Slovenia, short-term interest rates respond highly to the deviation of exchange rates, while monetary aggregate is highly sensitive to the deviation of inflation from its target. Both interest rates and monetary 
aggregate are responsive to inflation in Hungary and Romania.

Even though the bulk of the empirical literature are studies on developed countries, there has been a growing body of literature on developing countries. Sánchez-fung (2005) estimates a combination of Taylor and McCallum monetary policy rules for the Dominican Republic(DR). The results suggest that the central bank of the DR has been concerned with targeting the exchange rate. Elshamy (2012) and Apanisile and Ajilore (2013) employ co-integration approach in their monetary policy reaction function analyses. Elshamy (2012) estimates the monetary policy reaction function for Egypt using cointegration analysis. He estimates both the simple Taylor rule and its extension which includes the exchange rate. He finds the output gap, inflation and exchange rates to be statistically significant and to have the correct signs. He concludes that the inflation rate plays an important role in the conduct of monetary policy in Egypt. Apanisile and Ajilore (2013), also estimated a monetary policy reaction function for Nigeria using a co-integration approach. They concluded that monetary policy was conducted in Nigeria to achieve price stability. Lueangwilai (2012) and Were (2014) consider various types of the Taylor rule like the backwards and forward looking rules in analyzing monetary policy reaction functions. Lueangwilai (2012) examines monetary policy implementation in Thailand. He considers variants of the Taylor rule like contemporaneous, backward-looking and forward-looking. He concludes that the Bank of Thailand (BOT) is more concerned with contemporaneous economic condition than lagged interest rate, and that the BOT focuses more on exchange rate stabilistion as opposed to output stabilization. Were (2014), on the other hand, examines the monetary policy reaction function for Kenya over the period 1999 to 2011. He finds interest rate smoothing effect to be significant and monetary policy to be sensitive to output growth. However, monetary policy response to inflation is low. The evidence also supports a forward-looking monetary policy.

The objective of the study is to establish the nature of monetary policy in developing countries by analysing policy reaction functions. The study looks at the characteristics of monetary policy reaction functions through examinations of the estimated coefficients for statistical significance and correctness of signs. As studies from developing countries are relatively scarce as compared to developed economies, this study provides evidence from Ghana, a classic developing economy, to bridge the existing gap in the literature.

The rest of the study continues with Section 2 discussing the theoretical framework. The empirical methodology and data are described in Section 3. The empirical results are presented in Section 4 and Section 5 concludes.

\section{Theoretical Framework}

The question as to whether monetary policy should follow mechanical rules or the monetary authorities should respond to events in a discretionary manner has been subjected to intense debate over the years. The critics of monetary discretion argue that discretion does not lead to perfect outcomes not because monetary policy makers are uninformed, but because of not being well-motivated. Advocates of discretionary monetary policy also consider central bankers as being well-informed experts. However, they simply argue that these experts can perform better than any rule.

In the rules-versus-discretion debate, Keynesians support active discretionary monetary policies to keep an unstable economy on track. The Monetarists, on the other hand, see the need for a rule to ensure macroeconomic stability. They believe that monetary policy cannot be reliably used to counterbalance instabilities in economic activity in the short-run. They insist money supply affects money income after a long time lag. Any attempt therefore to use monetary policy as a tool of stabilisation will rather destabilise the economy. They recommend that the monetary authorities should avoid sharp policy swings and adopt the policy of attaining a consistent growth in the money supply in line with the growth in the Gross National Product (GNP). The problem of dynamic inconsistency arises out of the fact that there is a tradeoff between inflation and unemployment in the short-run but there is no such tradeoff in the long-run due to the adjustment of inflationary expectations. A central bank might break its promise not to allow inflation to increase beyond an ideal level in order to increase employment and output in the short-run. To get around this problem, a central bank should follow a monetary policy rule and increase the money supply at a low and constant rate. The idea of a monetary policy reaction function has been influenced largely by the seminal contribution of Taylor (1993). He formulated the Taylor rule which suggests that central banks should alter their interest rates in response to deviations of inflation and output from target. The original rule can be expressed by a simple equation as follows:

$$
r=2+\pi+0.5(\pi-2)+0.5(y-\bar{y})
$$

where, $r$ is the policy interest rate of the central bank, $\pi$ is the inflation rate, $y$ is the actual output and $\bar{y}$ is the potential output.

The rule recommends that the central bank should increase its policy rate whenever actual output rises above 
potential output or inflation is above its target. It also recommends a reduction in the policy rate whenever the opposite situations occur. In fact, this rule recommends that the policy rate should be raised 1.5 percentage points for every percentage point increase in inflation above targeted inflation and be raised by 0.5 percentage points for every percentage point increase in the output gap.

Ever since Taylor's (1993) postulation of a simple monetary policy rule variants of the rule have emerged. The question which usually confronts the monetary authorities is whether they should react to movements in expected future inflation, or they should look backwards and adjust the policy interest rate on the basis of past movements in inflation. Various versions of the forward looking Taylor's rule have been specified by some researchers like Rudebusch and Svensson (1999), Clarida, Gali, and Gertler (2000), Orphanides (2001), Batini and Nelson (2001). The one postulated by Clarida et al. (2000) is the most prominent among them. This rule, which is often used by researchers, describes the response of the central bank to inflation and output gaps.

Clarida et al. (2000) formulated the rule as follows:

$$
i_{t}^{*}=i^{*}+\beta\left(E\left(\pi_{t+n}\right)-\pi^{*}\right)+\gamma\left(E\left(y_{t+q}\right)\right)
$$

where $\mathrm{i}_{\mathrm{t}} *$ is the nominal interest rate target, $\mathrm{i} *$ is the long-run equilibrium nominal interest rate, $\pi_{\mathrm{t}+\mathrm{n}}$ denotes the annual rate of inflation between periods $t$ and $t+n, E\left(\pi_{t+n}\right)$ is the expected inflation rate between periods $t$ and $t+n$, $\pi^{*}$ is the target inflation rate, $\mathrm{y}_{\mathrm{t}+\mathrm{q}}$ denotes the average output gap between periods $\mathrm{t}$ and $\mathrm{t}+\mathrm{q}, \beta$ and $\gamma$ are parameters with values greater than zero.

Equation (2) indicates that the nominal interest rate target is a function of long-run equilibrium nominal interest rate, the gap between expected inflation and its target level, and the output gap. It shows that the central bank adjusts the interest rate in reaction to the deviation between the expected rate of inflation and the target rate of inflation and the output gap.

The McCallum rule, the alternative monetary policy rule proposed by McCallum (1987, 1993, 2006), describes the relationship between inflation and the growth in the money supply. The rule can be written as

$$
\Delta B_{t}=\Delta x_{t}^{*}-\Delta v B_{t}+\lambda\left(\Delta x_{t-1}^{*}-\Delta x_{t-1}\right)
$$

where $\Delta \mathrm{B}_{\mathrm{t}}$ is the percentage rate of growth of the monetary base per year; $\Delta v \mathrm{~B}_{\mathrm{t}}$ is the average base velocity growth rate over the previous four years; $\Delta \mathrm{x}_{\mathrm{t}}$ is the rate of growth of nominal GDP; $\Delta \mathrm{x}_{\mathrm{t}}{ }^{*}$ is the target rate of growth of nominal GDP. The target value $\Delta \mathrm{x}_{\mathrm{t}}{ }^{*}$ is the sum of the target inflation rate and the long-run average rate of growth of real GDP. $\lambda$ represents the monetary response factor.

Interest rate smoothing is the tendency of central banks to adjust the interest rate gradually rather than immediately to the level that is expected to most rapidly close the expected output gap and keep expected inflation on target. In fact, the Federal Reserves and other central banks tend to adjust interest rates in sequence of small steps in the same direction and rarely change the direction of interest rate movements. Following the criticism that policy responsiveness to macroeconomic developments is too little and too late, investigating interest rate smoothing is on the increase and now forms a greater part of the literature.

\section{The Empirical Methodology}

The study aims at establishing the characteristics of monetary policy by analysing the monetary policy response functions of developing countries. The study is carried out over a period of 11 years, that is 2002 to 2012. Ghana adopted inflation targeting regime in 2002 but made it officially known in 2007. The study therefore uses data from this country to establish the nature of monetary policy in developing countries.

Following Clarida, Gali, and Gertler (1998) and Peersman and Smets (1998), the following forward-looking simple Taylor rule with interest rate smoothing is specified.

$$
i_{t}=(1-\rho)\left[\bar{\imath}+\beta\left(E\left(\pi_{t+n} \mid I_{t}\right)-\pi\right)+\gamma E\left(y_{t}-\vec{y} \mid I_{t}\right)\right]+\rho i_{t-1}+\mu_{t}
$$

where $\overline{1}$ is the equilibrium nominal interest rate (i.e. the equilibrium real interest rate plus the inflation objective), $\pi_{t+n}$ is the annual inflation rate at time $(t+n), E$ is the expectation operator and $I_{t}$ stands for the information available to the central bank when it sets the policy interest rate.

This interest rate smoothing term is included because central banks seem to adjust the interest rate gradually bringing it towards its desired level. In order to estimate the reaction function, equation (4) is restated in terms of realized variables as follows:

$$
i_{t}=(1-\rho) \alpha+(1-\rho) \beta \pi_{t+n}+(1-\rho) \gamma\left(y_{t}-\bar{y}\right)+\rho i_{t-1}+\varepsilon_{t}
$$

where $\alpha=(\overline{1}-\beta \pi)$ and $\varepsilon_{\mathrm{t}}=-(1-\rho)\left[\beta\left(\pi_{\mathrm{t}+\mathrm{n}}-\mathrm{E}\left(\pi_{\mathrm{t}+\mathrm{n}} \mid \mathrm{I}_{\mathrm{t}}\right)\right)+\gamma\left(\mathrm{y}_{\mathrm{t}}-\overline{\mathrm{y}}-\mathrm{E}\left(\mathrm{y}_{\mathrm{t}}-\overline{\mathrm{y}}\right)\right)\right]+\mu_{\mathrm{t}}$.

The exchange rate is considered a crucial monetary policy variable in open economies. It is therefore included in 
the function as an additional explanatory variable. The sign of the coefficient is expected to be negative thus indicating that exchange rate depreciation is accompanied by a high interest rate while exchange rate appreciation leads to a low interest rate. Equation (5) is rewritten as follows:

$$
i_{t}=(1-\rho) \alpha+(1-\rho) \beta \pi_{t+n}+(1-\rho) \gamma\left(y_{t}-\bar{y}\right)+(1-\rho) \delta x_{t}+\rho i_{t-1}+\varepsilon_{t}
$$

where $x_{\mathrm{t}}$ represents the real effective exchange rate at time $\mathrm{t}$.

To simplify the empirical analysis equation (6) is finally rewritten as follows:

$$
i_{t}=b_{0}+b_{1} \pi_{t+n}+b_{2}\left(y_{t}-\bar{y}\right)+b_{3} x_{t}+b_{4} i_{t-1}+\varepsilon_{t} \quad \mathrm{~b}_{1}>0, \mathrm{~b}_{2}>0, \mathrm{~b}_{3}<0, \mathrm{~b}_{4}>0
$$

where $b_{0}=(1-\rho) \alpha ; b_{1}=(1-\rho) \beta ; b_{2}=(1-\rho) \gamma ; b_{3}=(1-\rho) \delta ;$ and $b_{4}=\rho$

The Dynamic Ordinary Least Squares (DOLS) is used as the method of estimation in order to avoid the problem of endogeneity of regressors. Exogeneous independent variables make Ordinary Least Squares (OLS) estimates unbiased. Prior to estimation, cointegration is tested among the variables using Johansen-type cointegration tests as a precaution against spurious regression. The data are quarterly series obtained from the International Financial Statistics of the International Monetary Fund. However, the data for real GDP is annual data obtained from World Bank Development Indicators converted to quarterly series in Eviews, using the constant-match average method. The output gap is obtained as the ratio of cycle output to trend output. The cycle and trend outputs estimates are obtained using the Hodrick-Prescott (HP) filter on the output data. The inflation rate is the quarterly data on core inflation rate computed from the consumer price index series. The policy rate is used as a single rate to represent all interest rates. This is based on the assumption that all interest rates move with the policy rate.

\section{Results}

The Johansen-type cointegration tests for the policy reaction function are performed using alternative lag orders of 2 and 3 periods in order to assess the robustness of the results. Table 1 reports the results. There are two types of tests: the trace test and the maximum eigen value test. It is clear from Table 1 that the null hypothesis of no cointegration is rejected in all cases at the $5 \%$ significance level. There is therefore a cointegrating relationship among the interest rate, the output gap, the inflation rate and the exchange rate.

Table 1. Cointegration tests (i, $\pi, y-\bar{y}, x)$

\begin{tabular}{llll}
\hline Lag & Null Hypothesis & Trace Test & Maximum Eigen Value Test \\
\hline 2 & $\mathrm{r}=0$ & 67.809 & 46.428 \\
& & $(0.0002)$ & $(0.0001)$ \\
3 & $\mathrm{r}=0$ & 57.483 & 38.744 \\
& & $(0.0048)$ & $(0.0012)$ \\
\hline
\end{tabular}

Note. $\mathrm{r}$ is the hypothesized number of cointegrating equations. The probability values are in parentheses.

Since cointegration is established the cointegrating vector in equation (7) is estimated using the DOLS method by adding $\Delta \pi_{\mathrm{t}+\mathrm{n}}, \Delta\left(\mathrm{y}_{\mathrm{t}}-\overline{\mathrm{y}}\right), \Delta \mathrm{x}_{\mathrm{t}}$ and $\Delta \mathrm{i}_{\mathrm{t}-1}$ and their leads and lags. The results are shown in Table 2 . The simple Taylor rule results indicate that the inflation rate coefficient is positive and statistically insignificant in all cases at the 5\% level of significance. The output gap coefficient has a negative sign contrary to expectations. It is statistically insignificant in both cases. It is also clear that the exchange rate coefficient is negative and statistically significant at the $10 \%$ level for $\mathrm{k}=2$, but positive and statistically insignificant for $\mathrm{k}=3$.

The forward-looking model results show that the inflation rate coefficient is insignificant and carries the correct positive sign for $\mathrm{k}=2$ but the wrong negative sign for $\mathrm{k}=3$. The output gap coefficient has the correct positive sign and is statistically insignificant in both cases. It is evident that the exchange rate coefficient has the correct negative sign in both cases but it is statistically significant for $\mathrm{k}=2$ at the $5 \%$ level but insignificant for $\mathrm{k}=3$.

With respect to the backward-looking model all the estimated coefficients carry the correct signs and are statistically insignificant. The coefficient of the lagged interest rate appears to be stable and statistically significant in all cases. All the fitted models have a high explanatory power (adjusted $\mathrm{R}^{2}=100$ percent). However, in terms of consistency and robustness of results the backward looking model appears to be the most appropriate policy reaction function for Ghana. 
Table 2. Dynamic OLS estimates of Taylor rules

\begin{tabular}{|c|c|c|c|c|c|c|c|}
\hline Lead and Lag & Specification & $\mathrm{b}_{0}$ & $\mathrm{~b}_{1}$ & $\mathrm{~b}_{2}$ & $\mathrm{~b}_{3}$ & $\mathrm{~b}_{4}$ & $\overline{\mathrm{R}}^{2}$ \\
\hline \multirow[t]{6}{*}{2} & Simple Taylor rule & $3.74 \mathrm{E}-12$ & $1.53 \mathrm{E}-13$ & $-2.16 \mathrm{E}-13$ & $-3.26 \mathrm{E}-14$ & 1.0000 & 1.0000 \\
\hline & & $(0.1016)$ & $(0.5663)$ & $(0.9651)$ & $(0.0903)$ & $(0.0000)$ & \\
\hline & Forward-looking inflation $(\mathrm{t}+2)$ & $9.31 \mathrm{E}-12$ & $2.66 \mathrm{E}-13$ & $7.28 \mathrm{E}-12$ & $-8.08 \mathrm{E}-14$ & 1.0000 & 1.0000 \\
\hline & & $(0.0375)$ & $(0.4411)$ & $(0.4839)$ & $(0.0370)$ & $(0.0000)$ & \\
\hline & Backward-looking inflation(t-2) & $8.94 \mathrm{E}-13$ & $2.49 \mathrm{E}-14$ & $4.79 \mathrm{E}-13$ & $-7.06 \mathrm{E}-15$ & 1.0000 & 1.0000 \\
\hline & & $(0.1255)$ & $(0.7252)$ & $(0.7848)$ & $(0.1252)$ & $(0.0000)$ & \\
\hline \multirow[t]{6}{*}{3} & Simple Taylor rule & $-7.31 \mathrm{E}-12$ & $6.05 \mathrm{E}-14$ & $-5.00 \mathrm{E}-12$ & $5.59 \mathrm{E}-14$ & 1.0000 & 1.0000 \\
\hline & & $(0.5217)$ & $(0.9544)$ & $(0.8049)$ & $(0.4976)$ & $(0.0000)$ & \\
\hline & Forward-looking inflation $(\mathrm{t}+2)$ & $5.79 \mathrm{E}-11$ & $-4.17 \mathrm{E}-13$ & $1.13 \mathrm{E}-10$ & $-4.47 \mathrm{E}-13$ & 1.0000 & 1.0000 \\
\hline & & $(0.4995)$ & $(0.9358)$ & $(0.7829)$ & $(0.4784)$ & $(0.0000)$ & \\
\hline & Backward-looking inflation(t-2) & $5.84 \mathrm{E}-11$ & $6.35 \mathrm{E}-12$ & $4.50 \mathrm{E}-11$ & $-4.62 \mathrm{E}-13$ & 1.0000 & 1.0000 \\
\hline & & $(0.2915)$ & $(0.4759)$ & $(0.7065)$ & $(0.2866)$ & $(0.0000)$ & \\
\hline
\end{tabular}

Note. The probability values are in parentheses.

\section{Conclusion}

In his seminal work, Taylor came out with a policy rule which allows the Federal Reserves to alter the policy rate in reaction to lagged inflation and real GDP gap. Thereafter, a number of studies have used and developed this policy rule to analyse the actions of central banks in developed countries. Empirical analyses of monetary policy rules of developing countries have been relatively scarce as compared to the advanced economies. This study therefore uses Ghanaian macroeconomic data to analyse the nature of monetary policy rules of developing countries.

The study uses the DOLS estimation technique and finds the central bank to follow a backward-looking Taylor rule. Even though the results are not significant, the evidence is that the central bank follows some form of policy rule and focuses more on past inflation than current or expected inflation. Although statistically insignificant the exchange rate turns out to have the correct negative sign which means the central bank restricts the money supply when the currency depreciates. The results indicate that the central bank has been pursuing inflation targeting monetary policy. In times of high inflation or positive output gap the central bank responds by reducing the money supply. The central bank follows a rule which targets inflation and makes some allowance for output stabilisation. The exchange rate appears to be playing a role in this stabilisation effort. The high significance of the coefficient of the lag of the dependent variable has been interpreted as an interest rate smoothing reaction by monetary authorities. The high $\mathrm{R}^{2}$ value of 1.00 is indicative that the model has a good fit.

The policy implications of this study are, first of all, the backward looking monetary policy stance of the central bank seems not to be a move in the right direction. Some studies in the literature have noted that having an independent central bank pursuing a forward looking monetary policy is a prerequisite for a successful inflation targeting regime. Second, the fact that depreciation of the currency leads to a contractionary monetary policy means the central bank pursues both inflation rate stabilisation and exchange rate stabilisation. In fact, another requirement for an effective implementation of inflation targeting monetary policy is for the central bank to gradually avoid targeting the exchange rate. Finally, the identification of a significant interest rate smoothing effect implies the central bank adjusts the interest rate gradually instead of effecting sharp changes with undesirable shocks to the economy. Further studies can consider using a panel data from several countries to shed more light on the behaviour of monetary policy reaction functions in the developing countries context.

\section{References}

Apanisile, O. T., \& Ajilore, T. (2013). Inflation Targeting Monetary Policy Rule in Nigeria: Estimates of the Policy Reaction Function. International Journal of Economics and Finance, 5(7).

Batini, N., \& Nelson, E. (2001). Optimal horizons for inflation targeting. Journal of Economic Dynamics and Control, 25(6-7), 891-910. https://doi.org/10.1016/S0165-1889(00)00060-9

Chevapatrakul, T. (2009). The Taylor Principle and Monetary Policy Approaching a Zero Bound on Nominal Rates: Quantile Regression Results for the United States and Japan. Journal of Money, Credit and Banking, 41(8). https://doi.org/10.1111/j.1538-4616.2009.00269.x 
Clarida, R., Gali, J., \& Gertler, M. (1998). Monetary policy rules in practice: Some international evidence. European Economic Review, 42, 1033-1067. https://doi.org/10.1016/S0014-2921(98)00016-6

Clarida, R., Gali, J., \& Gertler, M. (2000). Monetary policy rules and macroeconomic stability: Evidence and some theory. Quarterly Journal of Economics, 115, 147-180. https://doi.org/10.1162/003355300554692

Elshamy, H. M. (2012). Estimating the Monetary Policy Reaction Function in Egypt. Singidunum Journal of Applied Sciences, 9(2), 27-32. https://doi.org/10.5937/sjas1202027E

Esanov, A., Merkl, C., \& Vinhas de Souza, L. (2005). Monetary Policy Rules for Russia. Journal of Comparative Economics, 33(3), 484-499. https://doi.org/10.1016/j.jce.2005.05.003

Friedman, M. (1982). Monetary Policy: Theory and Practice. Journal of Money Credit and Banking, 14(1), 98-118. https://doi.org/10.2307/1991496

Ghatak, S., \& Moore, T. (2011). Monetary Policy Rules for Transition Economies: An Empirical Analysis. Review of Development Economics, 15(4), 714-728. https://doi.org/10.1111/j.1467-9361.2011.00638.x

Hsing, Y. (2004). Estimating the Bank of Japan's Monetary Policy Reaction Function. Banca Nazionale del Lavoro Quarterly Review, 57(229), 169-183.

Lueangwilai, K. (2012). Monetary Policy Rules and Exchange Rate Uncertainty: A Structural Investigation in Thailand. Procedia Economics and Finance, 2, 325-334. https://doi.org/10.1016/S2212-5671(12)00094-9

McCallum, B. (1987). The Case for Rules in the Conduct of Monetary Policy: A Concrete Example. Review of World Economics, 123(3), 415-429. https://doi.org/10.1007/BF02707752

McCallum, B. (1993). Specification and Analysis of a Monetary Policy Rule for Japan. NBER Working Paper, No. 4449. https://doi.org/10.3386/w4449

McCallum, B. (2006). Policy-Rule Retrospective on the Greenspan Era. Shadow Open Market Committee, Manusccript, May 8.

Orphanides, A. (2001). Monetary Policy Rules Based on Real-Time Data. American Economic Review, 91(4), 964-985. https://doi.org/10.1257/aer.91.4.964

Peersman, G., \& Smets, F. (1998). Uncertainty and the Taylor rule in a simple model of the Euro area economy, mimeo.

Rudebusch, G. D., \& Svensson, L. E. O. (1999). Policy Rules for Inflation Targeting. In T. B. John (ed.), A chapter in Monetary Policy Rules. Chicago: University of Chicago Press, 1999.

Sánchez-fung, J. R. (2005). Estimating a monetary policy reaction function for the Dominican Republic. International Economic Journal, 19, 563-577. https://doi.org/10.1080/10168730500382121

Taylor, J. B. (1993). Discretion versus Policy Rules in Practice. Carnegie-Rochester Conference Series on Public Policy, 39(1), 195-214. https://doi.org/10.1016/0167-2231(93)90009-L

Taylor, J. B. (2012). Monetary Policy Rules Work and Discretion Doesn't: A Tale of Two Eras. Journal of Money, Credit and Banking, 44(6), 1017-1032. https://doi.org/10.1111/j.1538-4616.2012.00521.x

Were, M. (2014). Empirical analysis of monetary policy reaction function in an emerging African market economy. International Journal of Economics and Business, 8(3). https://doi.org/10.1504/IJEBR.2014.064672

\section{Copyrights}

Copyright for this article is retained by the author(s), with first publication rights granted to the journal.

This is an open-access article distributed under the terms and conditions of the Creative Commons Attribution license (http://creativecommons.org/licenses/by/4.0/). 